\title{
O uso de vídeos como recurso pedagógico no ensino remoto
}

The use of videos as a pedagogical resource in remote learning

El uso de videos como recurso pedagógico en la enseñanza remota

Thais Fernanda dos Santos dos Santos ${ }^{1}$ Universidade Estadual do Oeste do Paraná

Susimeire Vivien Rosotti de Andrade ${ }^{2}$ Universidade Estadual do Oeste do Paraná

Resumo: A pandemia da COVID-19 ocasionou a substituição do ensino presencial pelo ensino remoto emergencial. Este artigo consiste num relato de experiência de uma professora do ensino fundamental durante a elaboração, acompanhamento e correção das atividades no município de Foz do Iguaçu (Paraná) em uma escola pública. Para tanto, realizou-se pesquisa bibliográfica que evidenciou a relação das tecnologias e o ensino remoto, apresentando como foram utilizados vídeos como recurso pedagógico num momento pandêmico que foi desafiador e enriquecedor para a prática pedagógica da professora. Conclui que as vivências do ensino remoto podem contribuir nas discussões de desenvolvimento de políticas educacionais voltadas para educação pública.

Palavra-chave: Tecnologias. Ensino remoto. Prática Pedagógica. Políticas educacionais. Pandemia da Covid-19.

Abstract: The COVID-19 pandemic led to the replacing of the regular teaching model by the remote teaching model. This paper consists in a report from a primary school teacher bringing her experience along the pandemic, regarding the preparation, execution and correction of the student's activities in a public school in the city of Foz do Iguaçu. Therefore, a bibliographic research was carried, concerning the connection between the technology and remote teaching, indicating how videos were used as a teaching resource in this challenging, although enriching, context for the teacher. As final regarding, it is considered that the remote teaching practices can promote the discussions regarding the development of public education.

Keywords: Technologies. Remote teaching. Pedagogical practices. Educational policies. Covid-19 pandemic.

Resumen: La pandemia de COVID-19 provocó la sustitución de la enseñanza presencial por la enseñanza remota de emergencia. Este artículo consiste en un relato de experiencia de una profesora de la enseñanza fundamental durante la elaboración, seguimiento y

\footnotetext{
${ }^{1}$ Mestranda em Ensino pela Universidade Estadual do Oeste do Paraná e professora da Educação Básica, Foz do Iguaçu, Paraná, Brasil. E-mail: thaisfernandadossantos573@gmail.com. Lattes: http://lattes.cnpq.br/1113242510520160. ORCID: https://orcid.org/0000-0003-1612-9098.

${ }^{2}$ Doutora em Educação Matemática pela Universidade Federal do Mato Grosso do Sul (UFMS) e professora e Integrante do corpo docente do Programa de Pós-Graduação stricto sensu em Ensino (PPGEn) da Universidade Estadual do Oeste do Paraná, Foz do Iguaçu, Paraná, Brasil. E-mail: susimeire.andrade@unioeste.br. Lattes: http://lattes.cnpq.br/7645006700133174. ORCID: https://orcid.org/0000-0001-9188-8620.
} 
corrección de las actividades en el municipio de Foz de Iguazú (Paraná) en una escuela pública. Para tanto, se realizó una investigación bibliográfica que evidenció la relación de las tecnologías y la enseñanza remota, presentando como fueron utilizados videos como recurso pedagógico en un momento pandémico que fue desafiante y enriquecedor para la práctica pedagógica de la profesora. Se concluye que las vivencias de la enseñanza remota pueden contribuir en las discusiones de desarrollo de políticas educativas orientadas a la educación pública.

Palabras clave: Tecnologías. Enseñanza remota. Práctica Pedagógica. Políticas educativas. Pandemia de Covid-19.

\section{Introdução}

A Pandemia do novo coronavírus - COVID-19, declarada pela Organização Mundial de Saúde em 2020 trouxe implicações para vários âmbitos da sociedade, inclusive a educação. Como medida para combater a disseminação do vírus, o Ministério da Educação declarou a substituição do ensino presencial pelo ensino remoto emergencial. Nas palavras de Saviani e Galvão (2021) “a expressão ensino remoto passou a ser usada como alternativa à educação a distância (EAD)" que "já tem existência estabelecida, coexistindo com a educação presencial como uma modalidade distinta, oferecida regularmente". Partindo disso, “o "ensino” remoto é posto como um substituto excepcionalmente adotado neste período de pandemia, em que a educação presencial se encontra interditada" (SAVIANI; GALVÃO, 202 1, p. 38).

Em abril, o Conselho Nacional de Educação, por meio do parecer $n^{0}$ 5/2020, determinou que as atividades não presenciais fossem computadas para fins de comprimento da carga horária anual mínima exigida. Várias medidas foram adotadas no âmbito educacional, como a ruptura da rotina escolar; a substituição do ensino presencial pelo ensino remoto; mudança nas condições de trabalho dos professores e da organização do trabalho pedagógico. Com isso, a instituição escolar passou a partilhar de responsabilidades ainda maiores relacionadas ao ensino e aprendizado com os familiares e/ou responsáveis pelos alunos.

Assim, no município de Foz do Iguaçu (Paraná) autoridades primeiramente determinaram a interrupção das atividades escolares por 15 dias, no entanto, devido ao aumento de casos, estendeu-se a suspensão das atividades escolares do dia 01/04/2020 a 30/04/2020 conforme Decreto Municipal $n^{\circ} 27.963$ de 15/03/2020, $n^{\circ} 27.994$ de 25/03/2020, nº 28.005 de 20/04/2020 e demais atualizações. Apesar de todas as medidas 
de distanciamento físico e isolamento social, o retorno do ensino presencial representava uma ameaça para os alunos, professores e comunidade escolar, portanto, deu-se início a entrega de atividades remotas.

Inicialmente, as atividades remotas foram elaboradas pelos profissionais da educação lotados na Secretaria Municipal de Educação (SMED), cabendo aos professores lotados nas escolas as funções de entregar, acompanhar via WhatsApp e corrigir as atividades das suas respectivas turmas.

O presente artigo baseado numa pesquisa bibliográfica discute o uso de tecnologias no ensino remoto, sua importância e desafios; o ensino remoto no Brasil em tempos de pandemia: descrição de uma proposta para o acompanhamento e correção das atividades no ensino remoto, em especial, o uso de vídeos desenvolvidos e utilizados como recurso pedagógico. A pesquisa finaliza com algumas considerações afirmando que o ensino remoto reforçou a necessidade da relação entre escola e família, pois o ensino e aprendizado é um trabalho conjunto que continua para além dos muros da escola. O sistema de educação precisa urgentemente de políticas educacionais para minimizar os problemas ocasionados, sobretudo os relacionados à qualidade e ao direito de acesso à educação, pois a pandemia agravou ainda mais a desigualdade presente na educação.

\section{Uso de tecnologias no ensino remoto}

Com o advento da pandemia que provocou a substituição do ensino presencial pelo ensino remoto, a escola e os professores assumiram novos desafios, sendo os professores convocados para implantar esse novo processo de ensino e aprendizagem com o uso de Tecnologias Digitais de Informação e Comunicação (TDIC) na educação básica.

Conforme o Parecer n ${ }^{\circ}$ 5/2020 divulgado pelo Conselho Nacional de Educação:

É necessário considerar propostas que não aumentem a desigualdade ao mesmo tempo em que utilizem a oportunidade trazida por novas tecnologias digitais de informação e comunicação para criar formas de diminuição das desigualdades de aprendizado (BRASIL, 2020, p. 3).

Conforme Assis (2009, p. 120) o uso de tecnologias no contexto escolar ainda é um desafio, pois deve-se considerar que o país é diverso e perversamente desigual. Para que sua implantação seja efetiva e com qualidade é indispensável cumprir certas medidas:

a) Recursos suficientes para escolas e universidades, aperfeiçoamento de suas propostas e paradigmas educacionais; b) Professores bem-preparados, assessorados e atualizados em novos conhecimentos e práticas pedagógicas; c) Políticas públicas consistentes e duradouras avaliadas continuamente e acessíveis aos meios de comunicação e à população. (ASSIS, 2009, p. 120). 
$\mathrm{Na}$ escola, percebe-se que o professor apresenta insegurança ao trabalhar com tecnologias, sendo necessária formação continuada adequada para lidar com as transformações. A tecnologia não deve ser vista como a responsável pelo ensino dos alunos, mas como uma ferramenta para que o professor leve o aluno a se apropriar dos conhecimentos científicos, filosóficos e artísticos produzidos pela humanidade em sua forma mais desenvolvida (MALANCHEN, 2020, p. 26). Em concordância com Moraes (2013, p. 23):

$\mathrm{O} / \mathrm{a}$ professor/a é um orientador/a do processo de ensino e de aprendizagem, por isto sua formação precisa ser mediada por um currículo crítico e de incentivo à reflexão e ao debate sobre sua prática e em interlocução com seus pares. Isso não ocorre de forma imediata, consiste em um processo contínuo durante a vida profissional. A utilização das mídias nesse processo pode contribuir para uma ajuda recíproca e colaborativa, fortalecendo o espaço de partilha e de autoria (MORAES, 2013, p. 23).

Assim, frente a esse desafio, o professor deve buscar aperfeiçoamento profissional e proporcionar aos alunos uma formação crítica e emancipatória para utilizar os recursos tecnológicos. Conforme Moraes "Não há como negar que o estudo das mídias no campo da educação precisa ser intensificado mediante um estreitamento do diálogo entre a cultura escolar e a cultura midiática” (MORAES, 2013, p. 25). Por mais que os professores apresentem resistência ao seu uso, durante o ensino remoto as mídias foram recursos tecnológicos indispensáveis.

A substituição do ensino presencial pelo ensino remoto exigiu uma renovação na prática docente, pois para que o aluno tivesse acesso aos conteúdos, os professores tiveram que utilizar uma diversidade de ferramentas tecnológicas. Por mais que o aluno tivesse sua atividade impressa, ele necessitava de uma explicação dos conteúdos e exercícios. Não se pode negar que as ferramentas como Meet, WhatsApp, Telegram, Youtube, entre outras, foram essenciais no processo de ensino e aprendizagem durante o ensino remoto.

Vale ressaltar que nem todos os professores tiveram uma formação direcionada para uso de ferramentas digitais e precisaram se reinventar.

O desafio do professor, portanto, é observar essas mudanças para compreendê-las, no âmbito de seu trabalho pedagógico, a fim de que possa ressignificá-lo, atualizá-lo. Isso exige um tempo mais longo para formação dos envolvidos no processo, com preparação de infraestrutura tecnológica que vise à aprendizagem. Entretanto, com a suspensão das aulas, o ensino remoto entra em cena como resposta à crise e o professor, sem tempo de parar para refletir, precisou agir na urgência (OLIVEIRA; SILVA; SILVA, 2020, p. 31 ).

Durante o ensino remoto, manter o contato com o aluno fora da sala de aula tornou-se essencial para o seu desenvolvimento, pois eles necessitam de motivação e 
acompanhamento para continuarem o processo educacional. Em meio a tantos desafios e incertezas, não se deve esquecer dos professores que se destacaram ao trilhar esse caminho do uso de novas ferramentas de trabalho e encontraram na tecnologia uma forma de manter a educação.

A pandemia afeta estudantes e professores, de modo que todos estão sofrendo modificações e interrupções em suas vidas, durante o período de isolamento social. Portanto, é preciso compreensão de ambos os lados, pois todos estão passando por momentos atípicos e de adaptação (RONDINI; PEDRO; DUARTE, 2020, p. 48).

Como professora da rede pública de ensino, ao longo da graduação e formação continuada, não tive uma formação direcionada para o uso de ferramentas tecnológicas no processo de ensino e aprendizagem, a pandemia exigiu mudanças que jamais imaginávamos que aconteceriam tão rápido no sistema de ensino. Se para os alunos que possuem acesso às mídias o ensino remoto foi desafiador, imagina então para aqueles alunos que não tinham acesso sequer à internet.

Os desafios que a educação brasileira tem enfrentado, no contexto da crise, envolvem fatores que não estão relacionados apenas à questão dos conteúdos programáticos ou aos critérios e à metodologia do processo avaliativo, pois englobam questões sociais, familiares e econômicas dos estudantes (RONDINI; PEDRO; DUARTE, 2020, p. 54).

Nosso sistema educacional já é precarizado e o ensino remoto improvisado contribuiu para o aumento das desigualdades de acesso e aprendizagem dos filhos das classes trabalhadoras (MALANCHEM, 2020, p. 26), pois na legislação todos tiveram acesso à educação de qualidade, mas na prática a realidade é outra.

\section{O uso de vídeos como recurso pedagógico no ensino remoto}

Em abril, o Conselho Nacional de Educação, por meio do parecer $n^{0}$ 5/2020, determinou que as atividades não presenciais seriam computadas para fins de comprimento da carga horária anual mínima exigida. "Por atividades não presenciais entende-se, nesse parecer, aquelas a serem realizadas pela instituição de ensino com os estudantes quando não for possível a presença física destes no ambiente escolar” (BRASIL, 2020, p. 6).

As atividades não presenciais poderiam ser desenvolvidas por meios digitais como: videoaula, uso de plataformas virtuais, redes sociais, aplicativos de mensagens, entre outros. Tais medidas visavam à mitigação dos impactos da pandemia na educação. “A realização de atividades pedagógicas não presenciais visa, em primeiro lugar, que se evite retrocesso de aprendizagem por parte dos estudantes e a perda do vínculo com a escola, o que pode levar à evasão e abandono" (BRASIL, 2020, p. 6). 
O Parecer $\mathrm{N}^{\circ}$ 5/2020 destaca que:

Sob este aspecto, é importante considerar as fragilidades e desigualdades estruturais da sociedade brasileira que agravam o cenário decorrente da pandemia em nosso país, em particular na educação, se observarmos as diferenças de proficiência, alfabetização e taxa líquida de matrícula relacionados a fatores socioeconômicos e étnico-raciais. Também, como parte desta desigualdade estrutural, cabe registrar as diferenças existentes em relação às condições de acesso ao mundo digital por parte dos estudantes e de suas famílias. Além disso, é relevante observar as consequências socioeconômicas que resultarão dos impactos da COVID19 na economia como, por exemplo, aumento da taxa de desemprego e redução da renda familiar. Todos estes aspectos demandam um olhar cuidadoso para as propostas de garantia dos direitos e objetivos de aprendizagem neste momento a fim de minimizar os impactos da pandemia na educação (BRASIL, 2020, p. 3).

Aos estudantes do Ensino Fundamental Anos iniciais, devido às dificuldades para acompanhar as aulas online e realizar as atividades, é indispensável a presença de um adulto para supervisão e mediação. Essa presença é importante para orientar e supervisionar o aluno, no entanto, não dispensa a presença do professor no processo educativo. O Parecer $\mathrm{N}^{\circ}$ 5/2020 destaca que:

Neste período de afastamento presencial, recomenda-se que as escolas orientem alunos e famílias a fazer um planejamento de estudos, com o acompanhamento do cumprimento das atividades pedagógicas não presenciais por mediadores familiares. O planejamento de estudos é também importante como registro e instrumento de constituição da memória de estudos, como um portfólio de atividades realizadas que podem contribuir na reconstituição de um fluxo sequenciado de trabalhos realizados pelos estudantes (BRASIL, 2020, p. 9).

Sobre o ensino não presencial nos Anos Iniciais, o Parecer destaca a importância de o professor orientar os pais e familiares sobre o desenvolvimento das atividades com os alunos.

O documento traz algumas possibilidades que podem ser adotadas pela escola e professores:

- $\quad$ aulas gravadas para televisão organizadas pela escola ou rede de ensino de acordo com o planejamento de aulas e conteúdos ou via plataformas digitais de organização de conteúdos;

- $\quad$ sistema de avaliação realizado a distância sob a orientação das redes, escolas e dos professores e, quando possível, com a supervisão dos pais acerca do aprendizado dos seus filhos;

- lista de atividades e exercícios, sequências didáticas, trilhas de aprendizagem por fluxo de complexidade relacionadas às habilidades e aos objetos de aprendizagem;

- $\quad$ orientações aos pais para realização de atividades relacionadas aos objetivos de aprendizagem e habilidades da proposta curricular;

- $\quad$ guias de orientação aos pais e estudantes sobre a organização das rotinas diárias;

- $\quad$ sugestões para que os pais realizem leituras para seus filhos; 
- utilização de horários de TV aberta com programas educativos compatíveis com as crianças desta idade e orientar os pais para o que elas possam assistir;

- $\quad$ elaboração de materiais impressos compatíveis com a idade da criança para realização de atividades (leitura, desenhos, pintura, recorte, dobradura, colagem, entre outros);

- distribuição de vídeos educativos (de curta duração) por meio de plataformas on-line, mas sem a necessidade de conexão simultânea seguidos de atividades a serem realizadas com a supervisão dos pais;

- realização de atividades on-line síncronas, regulares em relação aos objetos de conhecimento, de acordo com a disponibilidade tecnológica;

- oferta de atividades on-line assíncronas regulares em relação aos conteúdos, de acordo com a disponibilidade tecnológica e familiaridade do usuário;

- $\quad$ estudos dirigidos com supervisão dos pais;

- $\quad$ exercícios e dever de casa de acordo com os materiais didáticos utilizados pela escola;

- $\quad$ organização de grupos de pais, por meio de aplicativos de mensagens instantâneas e outros, conectando professores e as famílias; e

- guias de orientação às famílias e acompanhamento dos estudantes (BRASIL, 2020, p. 11-12).

Seguindo as orientações do Conselho Nacional de Educação, o município de Foz do Iguaçu suspendeu as aulas presenciais em março de 2020, dando início ao ensino remoto no mês de maio. No início, as atividades remotas foram elaboradas pelos professores lotados na Secretaria Municipal de Educação e encaminhadas para as cinquenta unidades de ensino. As atividades eram as mesmas para todas as escolas públicas. Ficou a cargo dos professores regentes de cada instituição de ensino a entrega, orientação e correção das atividades remotas impressas.

Sobre os aspectos legais da educação brasileira, Cunha, Silva e Silva (2020, p. 32) destacam que "sabe-se que, historicamente e em situações normais, esse direito já é negado a muitos pela desigualdade social marcante na sociedade brasileira. Com efeito, para alguns estudantes estar na escola é um desafio que antecede a aprendizagem”.

É visível que a população brasileira sofre com a falta de condições técnicas, nem todos possuem computador, internet de qualidade ou smartphones. Em concordância com Cunha, Silva e Silva:

Sendo assim, os alunos que não dispõem de aparelhos celulares que operem com eficiência os navegadores, aplicativos e plataformas utilizadas para o ensino remoto, não conseguirão acompanhar a contento. Igual dificuldade podem ter as famílias que não possuam aparelhos suficientes para a conexão de todos que precisem. Há ainda uma parte significativa dos usuários que o acesso à internet se dá por meio do compartilhamento com domicílios vizinhos. Situação que determina uma fragilidade na condição de incluído digital, preso à iminência constante de ser excluído (CUNHA, SILVA, SILVA 2020, p. 33). 
Foi justamente buscando uma aproximação com os alunos da rede municipal de educação de Foz do Iguaçu, principalmente daqueles em situação de vulnerabilidade, que a professora, primeira autora deste artigo, passou a gravar vídeos educativos de curta duração explicando os conteúdos e exercícios e, em seguida, os disponibilizando para os alunos e professores no aplicativo de comunicação WhatsApp e na plataforma de vídeos Youtube, conforme apresentado na Figura 1.

Figura 1: Aula de ciências sobre os tipos de energia.

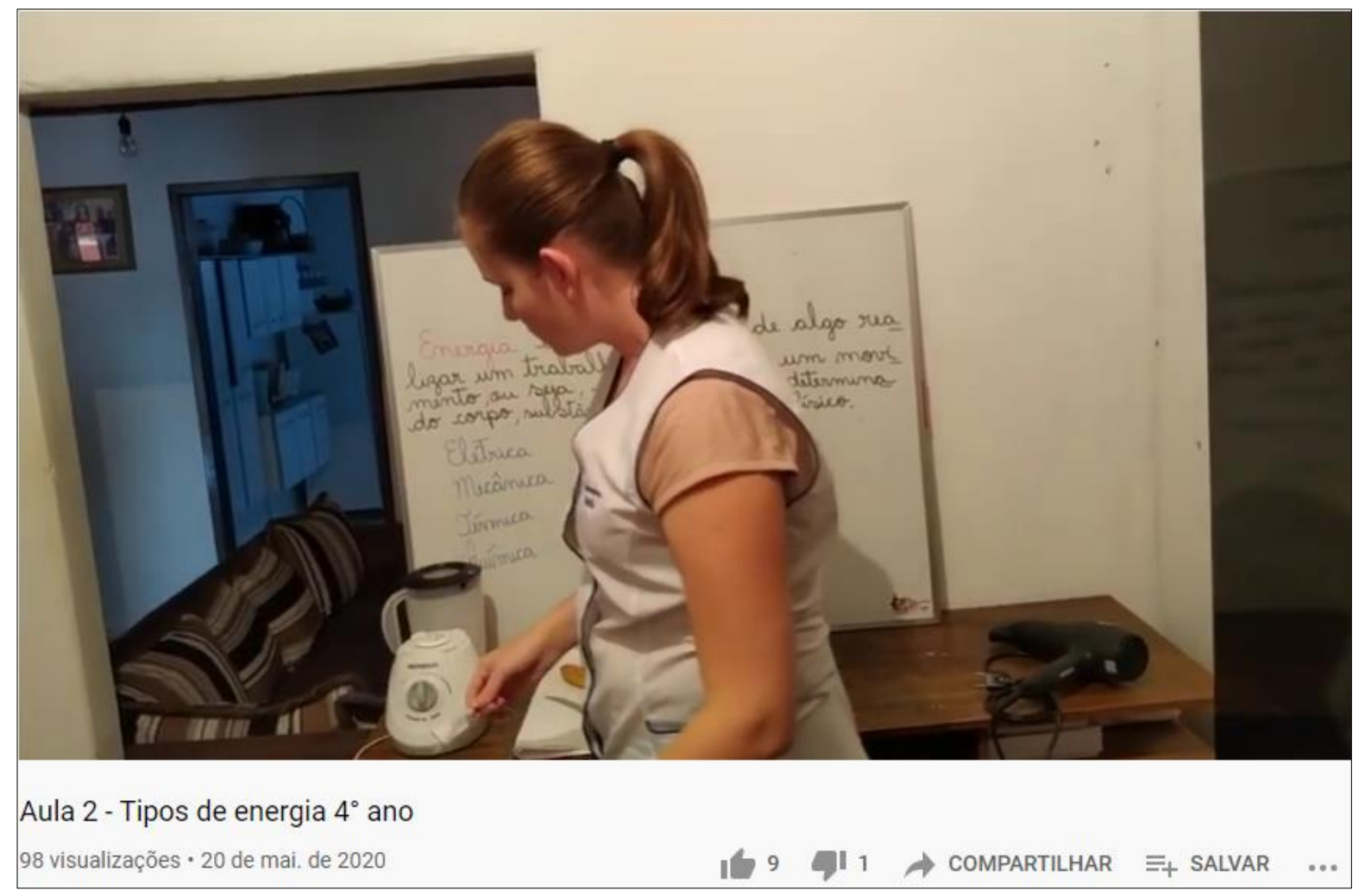

Fonte: Acervo das autoras.

De acordo com as disciplinas e seus conteúdos, a apresentação foi realizada com o uso de quadro branco e/ou elaborada no programa Microsoft PowerPoint, sendo então projetados numa televisão e gravados por meio do celular. Foram produzidos vídeos curtos e com resolução limitada para que pudessem ser suportados e encaminhados diretamente por meio do aplicativo WhatsApp. Esta foi uma solução encontrada para que os alunos que não tinham internet banda larga, apenas serviço de internet por telefonia móvel (pacote de dados), tivessem acesso aos vídeos. Para Oliveira; Silva e Silva:

As condições de renda e de vulnerabilidade socioeconômica, que implicam diretamente na falta de acesso à internet e a dispositivos digitais, revelam a necessidade de (re)pensarmos o ensino remoto como solução emergencial para a continuidade das atividades de ensino e aprendizagem (OLIVEIRA; SILVA, SILVA 2020, p. 34). 
Os vídeos gravados pela professora foram feitos com poucos recursos tecnológicos, pois ela não possuía equipamentos e nem formação adequada para lidar com tais recursos.

No ensino presencial os alunos convivem diariamente com seus professores, no ensino remoto emergencial isso não é possível. "Assim, entendemos que na educação escolar, o processo de ensino e aprendizagem, não ocorre de modo espontâneo, mecânico e individual, é uma ação que necessita da interação e mediação entre os indivíduos" (MALANCHEN, 2020, p. 27). Por considerar que não existe docência sem discência, o ensino deve ter como objetivo a aprendizagem, ensinar não é uma ação que ocorre isoladamente, mas sim uma ação que ocorre conjuntamente, pois o professor ao mesmo tempo que está ensinando, também está aprendendo (FREIRE, 1996).

A necessidade de gravar vídeos explicativos dos conteúdos e exercícios surgiu devido ao fato das atividades elaboradas pela Secretaria Municipal de Educação de Foz do Iguaçu não atenderem às especificidades da escola e dos alunos, uma vez que eram generalizadas para todas as instituições de ensino. Dentre as funções desenvolvidas pelo professor está o planejamento das aulas, para que o planejamento atenda o seu objetivo. É indispensável que o professor tenha conhecimento do Projeto Político Pedagógico da escola, assim como conhecimentos de didática, domínio dos conteúdos e saberes metodológicos.

$\mathrm{O}$ fato de as atividades remotas serem generalizadas para todas as instituições de ensino de Foz do Iguaçu, desconsiderou a função primordial do trabalho desenvolvido por cada professor, que é planejar aulas e atividades conforme as especificidades e necessidades educacionais dos alunos, assim como daqueles que que possuem alguma deficiência, doença ou síndrome.

Criar vídeos explicativos foi a solução encontrada pela professora, que empregando poucos recursos tecnológicos buscou elaborar um material pedagógico atrativo e significativos para os alunos e demais professores. Os conteúdos abordados nos vídeos são das disciplinas de português, matemática e ciências, elaborados para as turmas do $3^{\circ}$ ano e $4^{\circ}$ ano do Ensino Fundamental Anos Iniciais. A maioria dos vídeos apresentam uma explicação do conteúdo e exemplos de sua aplicação no cotidiano.

Considerando que nem todos os professores possuem facilidade para gravar vídeos, a autora disponibilizou-os nos grupos de WhatsApp para que outros colegas de profissão pudessem utilizá-los. O vídeo “Representação com material dourado” elaborado para turma de $4^{\circ}$ ano obteve mais de 950 visualizações na plataforma Youtube, conforme apresentado na figura 2 . 
Figura 2: Conhecendo o material dourado.

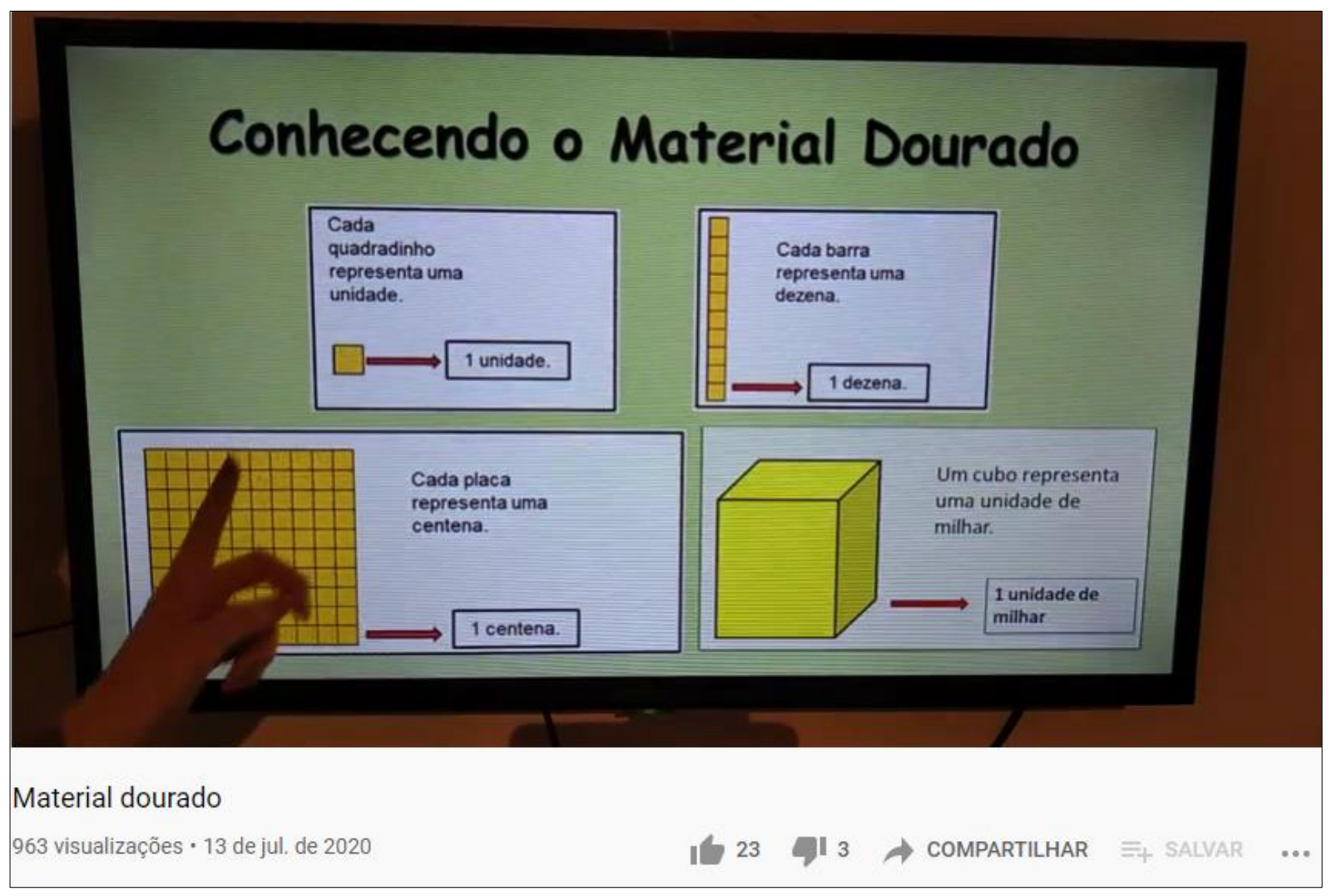

Fonte: Acervo das autoras.

A partir de meados de agosto a Secretaria de Educação de Foz do Iguaçu deixou de elaborar as atividades remotas para as instituições de ensino. Com isso, cada professor ficou responsável por elaborar suas atividades de acordo com o planejamento anual, as especificidades dos alunos e dificuldades observadas nos materiais anteriores.

Tal mudança possibilitou que o professor tivesse autonomia durante o ensino remoto, pois poderia elaborar suas atividades de acordo com o desenvolvimento de seus alunos. Como Malanchem (2020, p. 32) afirma "um processo de ensino e aprendizagem sem um diagnóstico e planejamento adequados está fadado ao fracasso”.

A produção de vídeos como recurso pedagógico foi uma forma encontrada para proporcionar a apropriação de conhecimentos pelos alunos num contexto emergencial de ensino. Mesmo sem dispor de equipamentos adequados, acesso à internet de qualidade, sem preparo para uso pedagógico de ferramentas tecnológicas, busquei disponibilizar uma orientação para as atividades, cumprindo meu papel docente de oferecer formação crítica, humana e emancipadora para os filhos da classe trabalhadora de uma escola pública. 


\section{Considerações finais}

O presente estudo partindo de uma pesquisa bibliográfico discutiu o uso de tecnologias no ensino remoto, sua importância e desafios; o ensino remoto no Brasil em tempos de pandemia: descrição de uma proposta para o acompanhamento e correção das atividades no ensino remoto, em especial, o uso de vídeos desenvolvidos e utilizados como recurso pedagógico.

A pesquisa concluiu que a pandemia da Covid-19 gerou implicações em diversos âmbitos da sociedade e seus impactos são visíveis na educação. A necessidade de medidas de segurança levou a substituição do ensino presencial pelo ensino remoto emergencial, uma forma encontrada para se dar continuidade ao ano letivo. As consequências, implicações e impactos do ensino remoto emergencial são significativos e ainda não foram dimensionados na sua totalidade.

Neste sentido, o ensino remoto está sendo desafiador para o sistema educacional, principalmente, para os professores que tiveram que se reinventar para que o processo de ensino e aprendizado pudesse ocorrer. Os profissionais da educação não tiveram nenhum preparo ou formação para ministrar aulas no ensino remoto, tiveram que utilizar recursos tecnológicos que não eram usados com tanta frequência na área da educação. Foram inúmeros os desafios enfrentados pelos professores, mas não devemos esquecer de citar o quanto foram criativos e encontraram possibilidades para resolver os problemas.

A participação da família na vida escolar dos alunos sempre foi necessária, no entanto, durante o ensino remoto sua participação foi indispensável para que o trabalho do professor fosse bem-sucedido. Ter a efetiva participação da família já é um desafio durante o ensino presencial, isso agravou durante o ensino remoto, pois os alunos ficaram dependentes dos familiares para realização das atividades.

O contexto educacional do Brasil é marcado pela desigualdade, na legislação é garantido o direito de acesso à educação e reforçam o princípio da igualdade de condições e permanência na escola, mas sabemos que a realidade é bem diferente, pois historicamente esse direito já é negado devido às desigualdades sociais.

O trabalho desvela um contexto complexo, uma educação marcada pelo ensino remoto emergencial, implantado às pressas e sem consideração com diversas realidades e condições da população brasileira. Mesmo com o esforço e dedicação dos profissionais da educação, o processo de ensino e aprendizagem não foi efetivo em todas as instituições de ensino. $\mathrm{O}$ contexto de pós-pandemia exigirá das autoridades medidas efetivas para reparação das perdas acarretadas pelo ensino remoto emergencial. 


\section{Referências bibliográficas}

ASSIS, R. Mídia e educação. In: VIVARTA, Veet (coord.). Infância E̊ Consumo: Estudos no campo da comunicação. Brasília, DF: ANDI; Instituto Alana, 2009, p. 119-132.

BRASIL. Parecer CNE/CP No: 5/2020. Reorganização do Calendário Escolar e da possibilidade de cômputo de atividades não presenciais para fins de cumprimento da carga horária mínima anual, em razão da Pandemia da COVID-19. Brasília: Conselho Nacional de Educação, 2020c. Disponível em: http:// portal.mec.gov.br/index.php?option=com_docman\&view=download\&alias=145011pcp005-20\&category slug=marco--2020-pdf\&Itemid=30192 . Acesso em 04 mai. 2021.

BRASIL. Lei N. ${ }^{\circ} 9.394$ de dezembro de 1996. Estabelece as diretrizes e bases da educação nacional. Brasília: Casa Civil, 1996.

CUNHA, L. F. F; SILVA, A. S; SILVA, A. P. O ensino remoto no Brasil em tempos de pandemia: diálogos acerca da qualidade e do direito e acesso à educação. Revista Com Censo: Estudos Educacionais do Distrito Federal, [S.l.], v. 7, n. 3, p. 27-37, ago. 2020. ISSN 2359-2494. Disponível em: http://www.periodicos.se.df.gov.br/index.php/comcenso/article/view/924. Acesso em: 08 jun. 2021.

FOZ DO IGUAÇU (PR). Decreto municipal nº 27.963, de 15 de março de 2020. Dispõe sobre as medidas de controle e prevenção para enfrentamento da emergência em saúde pública de importância internacional decorrente do Novo Coronavírus (COVID-19). Diário Oficial do Município de Foz do Iguaçu. Foz do Iguaçu, ano 22, n 3805, p. 2-3, 15 março 2020.

FREIRE, P. Pedagogia da autonomia: saberes necessários à prática educativa. São Paulo: Paz e Terra, 1996, pp. 23-28.

MALANCHEN, J. Oportunismo do Capital e a precarização da Educação Pública via Ead: Análise a partir da Pedagogia Histórico-Crítica. Revista Pedagogia Cotidiano Ressignificado. V. 1, n. 4, 2020. Disponível em: https://rpcr.com.br/index.php/revista_rpcr/article/view/1. Acesso em: 20 set. 2021.

MORAES, D. R. S. O Programa Mídias na Educação E Na Formação De Professores/As: Limites E Possibilidades. 222p. Tese de Doutorado em Educação. Universidade Estadual de Maringá. Orientadora: Profa. Dra. Teresa Kazuko Teruya. Maringá, PR, 2013.

OLIVEIRA, S. S; SILVA, O. S. F; SILVA, M. J. O. Educar na incerteza e na urgência: implicações do ensino remoto ao fazer docente e a reinvenção da sala de aula. Interfaces científicas. Aracaju, v. 10, n. 1, p. 25-40, 2020. Disponível em:

https://periodicos.set.edu.br/educacao/article/view/9239/4127. Acesso em: 03 mai. 2021. DOI: https://doi.org/10.17564/2316-3828.2020v10n1p25-40.

RONDINI, C. A; PEDRO, K. M; DUARTE, C. S. Pandemia da COVID-19 e o ensino remoto emergencial: mudanças na prática pedagógica. Interfaces científicas. Aracaju, v. 10, n. 1, p. 14-57, 2020. Disponível em: https://periodicos.set.edu.br/educacao/article/view/9085/4128. Acesso em: 03 mai. 2021. DOI: https://doi.org/10.17564/2316-3828.2020v10n1p41-57.

SAVIANI, D.; GALVÃO, A. C. Educação na pandemia: a falácia do “ensino" remoto. Revista Universidade e Sociedade. Brasília, n. 67, 2021. Disponível em:

https://www.andes.org.br/img/midias/Oe74d85d3ea4a065b283db72641d4ada_1609774477.pdf. Acesso em: 20 set. 2021. 